\title{
Pengembangan Kawasan Strategis Minapolitan Melalui Klasifikasi Wilayah di Kabupaten Kutai Kartanegara
}

\author{
Alya Sarah Maulida ${ }^{1}$, Candra Rizki Adiwibowo ${ }^{2}$, Ella Febby Prihantara ${ }^{3}$, Sitinur Amaliah ${ }^{4}$ \\ ${ }^{1}$ Institut Teknologi Department Of Urban and Regional Planning, Faculty of Civil and Planning Engineering, \\ Kalimantan Institute of Technology, Balikpapan. Email: 08161009@ student.itk.ac.id \\ ${ }^{2}$ Institut Teknologi Department Of Urban and Regional Planning, Faculty of Civil and Planning Engineering, \\ Kalimantan Institute of Technology, Balikpapan. Email: 08161015@ student.itk.ac.id \\ ${ }^{3}$ Institut Teknologi Department Of Urban and Regional Planning, Faculty of Civil and Planning Engineering, \\ Kalimantan Institute of Technology, Balikpapan. Email: 08161025@ student.itk.ac.id \\ ${ }^{4}$ Institut Teknologi Department Of Urban and Regional Planning, Faculty of Civil and Planning Engineering, \\ Kalimantan Institute of Technology, Balikpapan. Email: 08161069@ student.itk.ac.id
}

\begin{abstract}
Kutai Kartanegara Regency has 7 subdistricts which are included in the Minapolitan area, including Marang Kayu, Muara Badak, Loa Kulu, Loa Janan, Samboja, Muara Jawa and Anggana. In developing the Minapolitan Straegis Region, it can increase fish farming income so as to produce equality in each region with better quality of life and welfare. In carrying out the development, it is necessary to have a region or sub-district which is the center of Minsan Metropolitan services, in determining the Minapolitan Region Service Center in Kutai Kartanegara Regency, a scalogram analysis (Guttman Scale) is performed to determine the areas that have complete facilities related to Minapolitan and Marshall Central Index Index analysis ( ISM) to determine the service center of the Kutai Kartanegara District Minapolitan Area. Based on the two analyzes, a service center in the Kutai Kartanegara District was obtained, namely Anggana District with the type and number of complete facilities related to the Minapolitan Area. Based on these results it is possible to develop the area in Anggana Subdistrict which is the Minapolitan Area Service Center of Kutai Kartanegara Regency.
\end{abstract}

Keywords: Marshall Central Index, Minapolitan Area Service Center, Scalogram Analysis (Guttman Scale).

\begin{abstract}
Abstrak
Kabupaten Kutai Kartanegara Memiliki 7 Kecamatan yang termasuk dalam kawasan Minapolitan Kecamatan tersebut diantaranya adalah Marang Kayu, Muara Badak, Loa Kulu, Loa Janan, Samboja, Muara Jawa dan Anggana. Dalam pengembangan Kawasan Straegis Minapolitan dapat meningkatkan pendapatan pembudidayaan ikan sehingga menghasilkan kesetaraan terhadap setiap wilayah dengan kualitas hidup dan kesejahteraan masyarat yang lebih baik. Dalam melakukan pengembangan tersebut dibutuhkan daerah atau Kecamatan yang menjadi pusat pelayanan Kawsan Minapolitan, dalam menentukan Pusat Pelayanan Kawasan Minapolitan di Kabupaten Kutai Kartanegara maka dilakukan analisis skalogram (Skala Guttman) untuk mengetahui wilayah yang memiliki kelengkapan fasilitas yang berhubungan dengan minapolitan dan analisis Indeks Sentralitas Marshall (ISM) untuk menentukan pusat pelayanan Kawasan Minapolitan Kabupaten Kutai Kartanegara. Berdasarkan kedua alnalisi yang dilakukan maka diperoleh pusat pelayanan kawasan minapolitan Kabupaten Kutai Kartanegara yaitu Kecamatan Anggana dengan jenis dan jumlah fasilitas lengkap yang berhubungan dengan Kawasan Minapolitan. Berdasarkan hasil tersebut maka dapat dilakukan pengembangan wilayah pada Kecamatan Anggana yang merupakan Pusat Pelayanan Kawasan Minapolitan Kabupaten Kutai Kartanegara.
\end{abstract}

Kata Kunci: Analisis Indeks Sentralitas Marshall (ISM), Analisis Skalogram (Skala Guttman), Pusat Pelayanan Kawasan Minapolitan.

\section{Pendahuluan}




\section{Pengembangan Kawasan Strategis Minapolitan Melalui Klasifikasi Wilayah di Kabupaten Kutai Kartanegara}

Klasifikasi pengembangan kawasan minapolitan dalam penataan ruang secara garis besar diarahkan kepada pengolaan tata ruang suatu wilayah perikanan, khususnya kawasan sentra produksi perikanan nasional dan daerah (bappenas,2013). Perencanaan wilayah minapolitan merupakan suatu upaya untuk memanfaatkan lahan serta potensi yang ada dalam mengatasi permasalahan yang dihadapi dalam pengolaan dan pemanfaatan potensi secara kelautan (Permen 18 Tahun 2012). Sehingga dalam pengembangan kawasan minapolitan menjadi satu perwujudan pemerintah daerah dalam pembangunan daerah melalui pemberdayaan dan potensi unggul daerah serta menghasilkan percepatan ekonomi yang lebih efektif dan efesien.

Pengembangan kawasan strategis kelautan dan perikanan diharapkan dapat meningkatkan pendapatan pembudidayaan ikan sehingga menghasilkan kesetaraan terhadap setiap wilayah dan kualitas hidup dan kesejahteraan masyarakat menjadi lebih baik. Dalam melaksanakan kebijakan ini perlu ditetapkan wilayah-wilayah potensial yang masuk dalam pengembangan kawasan strategis minapolitan melalui analisis klasifikasi wilayah.

Proses klasifikasi kawasan merupakan proses analisis mengenai lahan dan pemanfaatan yang diukur berdasarkan karakteristik dan kemampuan lahan wilayah perencanaan (Ridha dkk, 2017). Dalam analisis klasifikais kawasan akan menghasilkan penentuan pusat dan sub pusat pelayanan khususnya kawasan minapolitan yang terbagi menjadi kegiatan produksi, pemasaran hingga pengolahan. Sejalan dengan hal tersebut, berdasarkan Keputusan Menteri Kelautan dan Perikanan RI Nomor 32/MEN/2010 ditetapkan sebagai Kabupaten/Koat di Provinsi Kalimantan Timur sebagai kawasan minapolitan.

Memiliki 7 (tujuh) wilayah potensial terhadap kawasan minapolitan yang terdiri Kecamatan Muara Jawa, Kecamatan Marang Kayu, Kecamatan Anggana, Kecamatan Samboja, Kecamatan Muara Badak, Kecamatan Loajanan, dan Kecamatan Loa Kulu berhasil memasarkan hasil perikanan hingga pasar internasional. Berdasarkan Laporan Statistik Kelautan dan Perikanan Kabupaten Kutai Kartanegara Tahun 2018, pemasaran terhadap ekspor internasional mencapai 1.684,233 ton dengan jenis komoditi betutu dan kepiting. Sehingga berdasarkan potensi tersebut diperlukan pengembangan kawasan strategis minapolitan melalui klasifikasi wilayah.

Dalam penelitian ini digunakan analisis wilayah dengan melalukan pembobotan terhadap pusat pelayanan yang memiliki kelengkapan fasilitas yang baik dan memadai. Adapun analisis yang digunakan adalah analisis skalogram (Skala Guttman) dan analisis Indeks Sentralitas Marshall (ISM) yang dapat menentukan pusat pelayanan dalam klasifikasi kawasan strategis minapolitan Kabupaten Kutai Kartanegara.

Analisis klasifikasi ini adalah analisis untuk menentukan pusat dan sub pusat pelayanan kawasan minapolitan di Kabupaten Kutai Kartanegara. Pusat pelayanan merupakan pusat dari segara kegiatan minapolitan, mulai dari produksi, pemasaran, hingga pengolahan. Oleh karena itu, pusat pelayanan harus memiliki kelengkapan fasilitas yang baik dan memadai. Analisis yang digunakan dalam menentukan pusat pelayanan adalah analisis skalogram atau yang biasa disebut Skala Guttman dan analisis Indeks Sentralitas Marshall (ISM).

Analisis skalogram digunakan untuk mengidentifikasi pusat-pusat pelayanan berdasarkan fasilitas yang dimiki. Selain itu, analisis ini juga untuk mengetahui kelengkapan fasilitas suatu wilayah. Fasilitas yang digunakan dalam analisis ini hanya fasilitas-fasilitas yang berhubungan langsung dengan kawasan minapolitan (Tussa'diah, 2014).

Selain menggunakan analisis skalogram, dapat juga digunakan analisis Indeks Sentralitas Marshall (ISM) dalam menentukan pusat pelayanan di Kawasan Minapolitan Kabupaten Kutai Kartanegara. Analisis ISM 


\section{Kartanegara}

menggunakan jumlah fasilitas yang ada kemudian ditentukan bobot dari masing-masing fasilitas tersebut.

Penentuan bobot menggunakan rumus sebagai berikut (Tussa'diah, 2014).

Ket:

$$
\mathbf{C}=\mathbf{t} / \mathbf{T}
$$

$\mathrm{C}=$ bobot/jenis fasilitas

$\mathrm{t}=$ nilai sentralitas tiap jenis fasilitas (diasumsikan nilainya 100)

$\mathrm{T}=$ jumlah satuan tiap jenis fasilitas

\section{Metode}

Metode pengumpulan data pada penelitian ini menggunakan teknik survei primer dan survei sekunder. Survei sekunder didapatkan dari dokumen Kutai Kartanegara Dalam Angka tahun 2018, sedangkan survei primer dilakukan untuk mengunpulkan data jumlah fasilitas minapolitan yang tidak tersedia di data tersebut. Teknik analisis pada penelitian ini menggunakan teknik analisis skalogram dan ISM.

\section{Hasil dan Pembahasan}

Analisis penentuan pusat pelayanan di kawasan strategis minapolitan Kabupaten Kutai Kartanegara menggunakan analisis skalogram dan analisis Indeks Sentralitas Marshall (ISM). Analisis skalogram digunakan untuk mengidentifikasi pusat-pusat pelayanan berdasarkan fasilitas yang dimiki. Selain itu, analisis ini juga untuk mengetahui kelengkapan fasilitas suatu wilayah. Fasilitas yang digunakan dalam analisis ini hanya fasilitas-fasilitas yang berhubungan langsung dengan kawasan minapolitan. Sedangkan, analisis ISM menggunakan jumlah fasilitas yang ada kemudian ditentukan bobot dari masing-masing fasilitas tersebut.

Pertama dilakukan analisis skalogram, pada analisis ini dilakukan perhitungan kelayakan analisis skalogram. Untuk mendapatkan perhitungan kelayakan ini dibutuhkan nilai error. Maka dilakukan interpretasi data jumlah fasilitas, bahwa angka 1 menunjukkan di tiap kecamatan terdapat fasilitas/infrastuktur, sedangkan angka 0 menunjukkan bahwa di tiap kecamatan tidak ada fasilitas/infrastuktur. Berikut ini adalah data jumlah fasilitas yang terdapat di Kawasan Minapolitan Kabupaten Kutai Kartanegara:

Tabel 1: Jumlah Fasilitas Kawasan Minapolitan di Kabupaten Kutai Kartanegara

\begin{tabular}{cccccccccc}
\hline Kecamatan & Kolam & $\begin{array}{c}\text { Keram } \\
\text { ba }\end{array}$ & $\begin{array}{c}\text { Tempat } \\
\text { Pembe } \\
\text { nihan } \\
\text { Udang }\end{array}$ & Sawah & $\begin{array}{c}\text { Pasar } \\
\text { Ikan } \\
\text { dan } \\
\text { TPI }\end{array}$ & $\begin{array}{c}\text { Gudang } \\
\text { Pengep } \\
\text { akan } \\
\text { Udang }\end{array}$ & $\begin{array}{c}\text { Pabrik } \\
\text { Es }\end{array}$ & $\begin{array}{c}\text { Lembaga } \\
\text { Masyarak } \\
\text { at }\end{array}$ & $\begin{array}{c}\text { Juml } \\
\text { ah }\end{array}$ \\
\hline Samboja & 115 & 0 & 0 & 6 & 8 & 0 & 0 & 65 & 194 \\
\hline Loa Janan & 273 & 97 & 0 & 0 & 2 & 0 & 0 & 0 & 372 \\
\hline Loa Kulu & 352 & 588 & 0 & 0 & 0 & 0 & 0 & 38 & 978 \\
\hline Anggana & 45 & 0 & 0 & 10 & 1 & 1 & 1 & 113 & 171 \\
\hline $\begin{array}{c}\text { Muara } \\
\text { Badak }\end{array}$ & 270 & 0 & 1 & 0 & 0 & 0 & 0 & 50 & 321 \\
\hline $\begin{array}{c}\text { Marang } \\
\text { Kayu }\end{array}$ & 199 & 0 & 0 & 0 & 2 & 0 & 0 & 19 & 220 \\
\hline $\begin{array}{c}\text { Muara } \\
\text { Jawa }\end{array}$ & 75 & 0 & 0 & 0 & 0 & 0 & 0 & 65 & 140 \\
\hline \begin{tabular}{l} 
Jumlah \\
\hline
\end{tabular} & 1.329 & 685 & 1 & 16 & 13 & 1 & 1 & 350 & 2.396 \\
\hline & & & Sumber: Badan Pusat Statistik, 2019 & & &
\end{tabular}


Pengembangan Kawasan Strategis Minapolitan Melalui Klasifikasi Wilayah di Kabupaten Kutai

\section{Kartanegara}

Lalu, dilakukan interpretasi data jumlah fasilitas sebagai berikut:

Tabel 2: Interpretasi Data Jumlah Fasilitas Kawasan Minapolitan di Kabupaten Kutai Kartanegara

\begin{tabular}{lcccccccccc}
\hline $\begin{array}{l}\text { Kecamat } \\
\text { an }\end{array}$ & Kolam & $\begin{array}{c}\text { Lemba } \\
\text { Masyar } \\
\text { akat }\end{array}$ & $\begin{array}{c}\text { Pasar } \\
\text { Ikan } \\
\text { dan } \\
\text { TPI }\end{array}$ & Sawah & $\begin{array}{c}\text { Kera } \\
\text { mba }\end{array}$ & $\begin{array}{c}\text { Gudang } \\
\text { Pengepa } \\
\text { kan } \\
\text { Udang }\end{array}$ & $\begin{array}{c}\text { Pab } \\
\text { rik } \\
\text { Es }\end{array}$ & $\begin{array}{c}\text { Tempat } \\
\text { Pembe } \\
\text { nihan } \\
\text { Udang }\end{array}$ & $\begin{array}{c}\text { Jumla } \\
\text { h }\end{array}$ & Error \\
\hline $\begin{array}{l}\text { Anggana } \\
\text { Samboja }\end{array}$ & 1 & 1 & 1 & 1 & 0 & 1 & 1 & 0 & 6 & 2 \\
\hline $\begin{array}{l}\text { Marang } \\
\text { Kayu }\end{array}$ & 1 & 1 & 1 & 1 & 0 & 0 & 0 & 0 & 4 & 0 \\
\hline $\begin{array}{l}\text { Muara } \\
\text { Badak }\end{array}$ & 1 & 1 & 1 & 0 & 0 & 0 & 0 & 0 & 3 & 0 \\
\hline $\begin{array}{l}\text { Loa } \\
\text { Janan }\end{array}$ & 1 & 0 & 1 & 0 & 1 & 0 & 0 & 0 & 3 & 2 \\
\hline $\begin{array}{l}\text { Loa } \\
\text { Kulu }\end{array}$ & 1 & 1 & 0 & 0 & 1 & 0 & 0 & 0 & 3 & 2 \\
\hline $\begin{array}{l}\text { Muara } \\
\text { Jawa }\end{array}$ & 1 & 1 & 0 & 0 & 0 & 0 & 0 & 0 & 2 & 0 \\
\hline \begin{tabular}{l} 
Jumlah \\
\hline
\end{tabular} & 7 & 6 & 4 & 2 & 2 & 1 & 1 & 1 & 24 & 8 \\
\hline
\end{tabular}

Lalu, setelah didapatkan jumlah error dari data maka dilakukan perhitungan kelayakan skalogram. Berdasarkan Tussa'diah (2014) perhitungan ini bertujuan untuk mengetahui apakah data yang ada dapat digunakan untuk menghitung skalogramnya. Koefisien yang dianggap layak adalah apabila bernilai dari 0,9 hingga 1. Rumus yang digunakan dalam menghitung kelayakan skalogram adalah rumus coeffisien of reproducibility (COR) sebagai berikut:

Keterangan:

$$
\operatorname{COR}=1-\frac{\sum e}{N x k}
$$

$\mathrm{e}=$ jumlah kesalahan (error)

$\mathrm{N}=$ jumlah kecamatan

$\mathrm{K}=$ jumlah fasilitas

Berikut ini adalah hasil dari perhitungannya:

$$
\begin{aligned}
\text { COR } & =1-\frac{8}{(7 \times 24)} \\
& =1-0,04 \\
& =0,96
\end{aligned}
$$

Berdasarkan hasil dari perhitungan nilai COR, didapatkan hasil 0,96 yang berarti data tersebut layak untuk dianalisis. Kemudian, kecamatan akan diurutkan berdasarkan jumlah fasilitasnya. Banyaknya hierarki dan panjang hierarki ditentukan dari hasil perhitungan sebagai berikut (Tussa'diah, 2014).

\section{Banyak hierarki $=1+3,3 \log n$}

Ket:

$\mathrm{n}=$ jumlah kecamatan 


\section{Kartanegara}

Maka dari hasil perhitungan menggunakan rumus tersebut didapatkan didapatkan hasil banyak hierarki adalah 4. Berikut ini adalah hasil perhitungannya:

Banyak kelas $=1+3,3 \log 7$

$$
\begin{aligned}
& =1+3,3(0,845) \\
& =3,78 \\
& =4
\end{aligned}
$$

Kemudian, dilakukan perhitungan panjang kelas interval. Berikut ini adalah rumus perhitungan panjang kelas interval (Tussa'diah, 2014):

Panjang kelas $=\frac{(\text { Nilaj Tertinggi }- \text { Nilaj Terendah })}{\text { Banyak Hierarki }}$

Panjang kelas $=\frac{(6-2)}{4}$

$$
=1
$$

Dari rumus tersebut kemudian didapatkan hasil panjang kelas interval sebesar 901. Setelah didapatkan panjang kelasnya maka didapatkan panjang kelas untuk setiap hierarki adalah sebagai berikut:

1. Hierarki $1=5,01-6$

2. Hierarki $2=4,01-5$

3. Hierarki $3=3,01-4$

4. Hierarki $4=2-3$

Berikut ini adalah hierarki pelayanan kawasan minapolitan di Kabupaten Kutai Kartanegara:

Tabel 3: Hierarki Pelayanan Kawasan Minapolitan Kabupaten Kutai Kartanegara

\begin{tabular}{ccc}
\hline Kecamatan & Jumlah & Hierarki \\
\hline Anggana & 6 & Hierarki 1 \\
\hline Samboja & 4 & Hierarki 3 \\
\hline Marang Kayu & 3 & Hierarki 4 \\
\hline Muara Badak & 3 & Hierarki 4 \\
\hline Loa Janan & 3 & Hierarki 4 \\
\hline Loa Kulu & 3 & Hierarki 4 \\
Muara Jawa & 2 & Hierarki 4
\end{tabular}

Dari hasil tersebut dapat dilihat bahwa kecamatan yang terdapat pada hierarki 1 adalah Kecamatan Anggana. Kemudian kecamatan pada hierarki 3 adalah Kecamatan Samboja. Dan pada hierarki 4 terdapat 5 kecamatan yaitu Kecamatan Marang Kayu, Kecamatan Muara Badak, Kecamatan Loa Janan, Kecamatan Loa Kulu dan Kecamatan Muara Jawa. Tidak terdapat kecamatan pada hierarki 2.

Kecamatan yang berada pada hierarki 1 mempunyai potensi untuk menjadi pusat pelayanan Kawasan Minapolitan di Kabupaten Kutai Kartanegara karena memiliki jenis dan jumlah fasilitas yang pendukung yang lengkap. Sedangkan kecamatan yang berada pada hierarki 3 dan 4 memiliki peran sebagai kecamatan penyokong atau kecamatan pendukung.

Selanjutnya dilakukan analisis Indeks Sentralitas Marshall (ISM). Pada analisis ini pertama-tama dilakukan perhitungan penentuan bobot fasilitas menggunakan rumus sebagai berikut (Tussa'diah, 2014):

Ket:

$$
\mathbf{C}=\mathbf{t} / \mathbf{T}
$$

$\mathrm{C}=$ bobot/jenis fasilitas

$\mathrm{t}=$ nilai sentralitas tiap jenis fasilitas (diasumsikan nilainya 100) 
Pengembangan Kawasan Strategis Minapolitan Melalui Klasifikasi Wilayah di Kabupaten Kutai Kartanegara

$\mathrm{T}=$ jumlah satuan tiap jenis fasilitas

Berikut ini adalah Tabel 4 mengenai perhitungan bobot tiap jenis sarana yang ada di Kawasan Minapolitan Kabupaten Kutai Kartanegara:

Tabel 4: Bobot Sarana Kawasan Minapolitan di Kabupaten Kutai Kartanegara

\begin{tabular}{cccccccccc}
\hline $\begin{array}{c}\text { Kecamata } \\
\mathbf{n}\end{array}$ & $\begin{array}{c}\text { Jumlah } \\
\text { Rumah } \\
\text { Tangga } \\
\text { Perikanan }\end{array}$ & Kolam & $\begin{array}{c}\text { Kera } \\
\text { mba }\end{array}$ & $\begin{array}{c}\text { Tempat } \\
\text { Pembe } \\
\text { nihan } \\
\text { Udang }\end{array}$ & $\begin{array}{c}\text { Sawa } \\
\mathbf{h}\end{array}$ & $\begin{array}{c}\text { Pasar } \\
\text { Ikan } \\
\text { dan } \\
\text { TPI }\end{array}$ & $\begin{array}{c}\text { Gudang } \\
\text { Pengepa } \\
\text { kan } \\
\text { Udang }\end{array}$ & $\begin{array}{c}\text { Pabrik } \\
\text { Es }\end{array}$ & $\begin{array}{c}\text { Lemba } \\
\text { Masyar } \\
\text { akat }\end{array}$ \\
\hline Samboja & 2.824 & 115 & 0 & 0 & 6 & 8 & 0 & 0 & 65 \\
\hline Loa Janan & 2.974 & 273 & 97 & 0 & 0 & 2 & 0 & 0 & 0 \\
\hline Loa Kulu & 62 & 352 & 588 & 0 & 0 & 0 & 0 & 0 & 38 \\
\hline Anggana & 58 & 45 & 0 & 0 & 10 & 1 & 1 & 1 & 113 \\
\hline $\begin{array}{c}\text { Muara } \\
\text { Badak }\end{array}$ & 3.991 & 270 & 0 & 1 & 0 & 0 & 0 & 0 & 50 \\
\hline $\begin{array}{c}\text { Marang } \\
\text { Kayu }\end{array}$ & 1.698 & 199 & 0 & 0 & 0 & 2 & 0 & 0 & 19 \\
\hline $\begin{array}{c}\text { Muara } \\
\text { Jawa }\end{array}$ & 3.262 & 75 & 0 & 0 & 0 & 0 & 0 & 0 & 65 \\
\hline Jumlah & 14.869 & 1.329 & 685 & 1 & 16 & 13 & 1 & 1 & 350 \\
\hline Sentralitas & 100 & 100 & 100 & 100 & 100 & 100 & 100 & 100 & 100 \\
\hline Bobot & 0,007 & 0.075 & 0.146 & 100 & 6.25 & 7.692 & 100 & 100 & 0.286 \\
\hline
\end{tabular}

Setelah dilakukan perhitungan bobot, kemudian hasil dari bobot tersebut dimasukkan dalam perhitungan indeks sentralitas yaitu dengan mengkali nilai bobot dengan jumlah masing-masing fasilitas. Berikut ini adalah Tabel mengenai perhitungan indeks sentralitas di Kawasan Minapolitan Kabupaten Kutai Kartanegara:

Tabel 5: Indeks Sentralitas di Kawasan Minapolitan Kabupaten Kutai Kartanegara

\begin{tabular}{|c|c|c|c|c|c|c|c|c|c|c|}
\hline $\begin{array}{c}\text { Kecamat } \\
\text { an }\end{array}$ & $\begin{array}{c}\text { Jumlah } \\
\text { Rumah } \\
\text { Tangga } \\
\text { Perika } \\
\text { nan }\end{array}$ & Kolam & $\begin{array}{c}\text { Keram } \\
\text { ba }\end{array}$ & $\begin{array}{c}\text { Tempat } \\
\text { Pembe } \\
\text { nihan } \\
\text { Udang }\end{array}$ & $\begin{array}{c}\text { Sawa } \\
\mathbf{h}\end{array}$ & $\begin{array}{c}\text { Pasar } \\
\text { Ikan } \\
\text { dan } \\
\text { TPI }\end{array}$ & $\begin{array}{c}\text { Guda } \\
\text { ng } \\
\text { Penge } \\
\text { pakan } \\
\text { Udang }\end{array}$ & $\begin{array}{c}\text { Pabrik } \\
\text { Es }\end{array}$ & $\begin{array}{c}\text { Lemb } \\
\text { aga } \\
\text { Masya } \\
\text { rakat }\end{array}$ & Jumlah \\
\hline Anggana & 26,841 & 3,386 & 0 & 0 & 62,5 & 7,692 & 100 & 100 & 32,286 & 332,705 \\
\hline $\begin{array}{l}\text { Muara } \\
\text { Badak }\end{array}$ & 21,938 & 20,316 & 0 & 100 & 0 & 0 & 0 & 0 & 14,286 & 156,540 \\
\hline Samboja & 18,993 & 8,653 & 0 & 0 & 37,5 & 61,538 & 0 & 0 & 18,571 & 145,255 \\
\hline Loa Kulu & 0,390 & 26,486 & 85,839 & 0 & 0 & 0 & 0 & 0 & 10,857 & 123,572 \\
\hline $\begin{array}{l}\text { Loa } \\
\text { Janan }\end{array}$ & 0,417 & 20,542 & 14,161 & 0 & 0 & 15,385 & 0 & 0 & 0 & 50,505 \\
\hline $\begin{array}{l}\text { Marang } \\
\text { Kayu }\end{array}$ & 11,420 & 14,974 & 0 & 0 & 0 & 15,385 & 0 & 0 & 5,429 & 47,208 \\
\hline Muara & 20,001 & 5,643 & 0 & 0 & 0 & 0 & 0 & 0 & 18,571 & 44,215 \\
\hline
\end{tabular}


Pengembangan Kawasan Strategis Minapolitan Melalui Klasifikasi Wilayah di Kabupaten Kutai Kartanegara

\section{Jawa}

Sumber: Analisis Penulis, 2019

Setelah didapatkan bobot dari masing-masing fasilitas, kemudian dilakukan perhitungan untuk menentukan jumlah hierarki dan panjang kelas hierarkinya. Berikut ini adalah perhitungannya (Tussa'diah, 2014):

Ket:

\section{Banyak hierarki $=1+3,3 \log n$}

$\mathrm{n}=$ jumlah kecamatan

Maka dari hasil perhitungan menggunakan rumus tersebut didapatkan didapatkan hasil banyak hierarki adalah 4. Berikut ini adalah hasil perhitungannya:

Banyak kelas $=1+3,3 \log 7$

$$
\begin{aligned}
& =1+3,3(0,845) \\
& =3,78 \\
& =4
\end{aligned}
$$

Kemudian, dilakukan perhitungan panjang kelas interval. Berikut ini adalah rumus perhitungan panjang kelas interval:

Panjang kelas $=\frac{(\text { Jumlah bobot tertinggi }- \text { Jumlah bobot terend ah) }}{\text { Banyak Hjerarki }}$

Panjang kelas $=\frac{(332,705-44,215)}{4}$

$$
=72,1225
$$

Dari rumus tersebut kemudian didapatkan hasil panjang kelas interval sebesar 56,065. Setelah didapatkan panjang kelasnya maka didapatkan panjang kelas untuk setiap hierarki adalah sebagai berikut:

1. Hierarki $1=260,5825-332,705$

2. Hierarki $2=188,46-260,5825$

3. Hierarki $3=116,3375-188,46$

4. Hierarki $4=44,215-116,3375$

Berikut ini adalah hierarki pelayanan kawasan minapolitan di Kabupaten Kutai Kartanegara:

Tabel 6: Hierarki Pelayanan Kawasan Minapolitan Kabupaten Kutai Kartanegara

\begin{tabular}{lcl}
\hline \multicolumn{1}{c}{ Kecamatan } & Jumlah & Hierarki \\
\hline Anggana & 332,705 & Hierarki 1 \\
\hline Muara Badak & 156,540 & Hierarki 3 \\
\hline Samboja & 145,255 & Hierarki 3 \\
\hline Loa Kulu & 123,572 & Hierarki 3 \\
\hline Loa Janan & 50,505 & Hierarki 4 \\
\hline Marang Kayu & 47,208 & Hierarki 4 \\
\hline Muara Jawa & 44,215 & Hierarki 4
\end{tabular}

Dari Tabel 6. dapat dilihat bahwa kecamatan yang berada pada hierarki 1 adalah Kecamatan Anggana. Terdapat 3 kecamatan pada hierarki 3 yaitu Kecamatan Muara Badak, Kecamatan Samboja, dan Kecamatan Loa Kulu. Sedangkan pada hierarki 4 terdapat 3 kecamatan yaitu Kecamatan Loa Janan, Kecamatan Marang Kayu dan Kecamatan Muara Jawa. Kecamatan yang berada pada hierarki 1 
mempunyai potensi untuk menjadi pusat pelayanan Kawasan Minapolitan di Kabupaten Kutai Kartanegara karena memiliki jenis dan jumlah fasilitas yang pendukung yang lengkap. Sedangkan kecamatan yang berada pada hierarki 3 dan 4 memiliki peran sebagai kecamatan penyokong atau kecamatan pendukung.

Dari kedua analisis yang telah dilakukan dapat disimpulkan bahwa Kecamatan Anggana merupakan kecamatan yang berpotensi sebagai pusat pelayanan kawasan minapolitan di Kecamatan Kutai Kartanegara. Hal ini disebabkan dari analisis skalogram dan analisis ISM Kecamatan Anggana menempati hierarki 1. Sedangkan 6 kecamatan lainnya yaitu Kecamatan Muara Badak, Kecamatan Samboja, Kecamatan Loa Kulu, Kecamatan Loa Janan, Kecamatan Marang Kayu dan Kecamatan Muara Jawa merupakan kecamatan dengan peran sebagai penyokong pusat pelayanan di di kawasan minapolitan Kabupaten Kutai Kartanegara.

\section{Kesimpulan}

Kesimpulan yang diperoleh dari pembahasan yang telah dilakukan yaitu Dalam menentukan klasifikasi kawasan strategis minapolitan di Kabupaten Kutai Kartanegara dilakukan analisis skalogram (Skala Guttman) untuk mengetahui wilayah yang memiliki kelengkapan fasilitas yang berhubungan dengan minapolitan dan analisis Indeks Sentralitas Marshall (ISM) untuk menentukan pusat pelayanan yang mana hasil dari kedua analisis tersebut diperoleh Kecamatan Anggana sebagai Hierarki 1 yang berpotensi sebagai pusat pelayanan Kawasan Minapolitan di Kabupaten Kutai Kartanegara dikarenakan memiliki jenis dan jumlah fasilitas lengkap yang berhubungan dengan Kawasan Minapolitan. Kemudian untuk 6 kawasan selain hierarki 1 merupakan kawasan yang berfungsi sebagai penyokong pusat pelayanan Minapolitan Kabupaten Kutai Kartanegara. Berdasarkan hasil analisis tersebut maka dapat dilakukan pengembangan pada Kecamatan Anggana yang dapat meningkatkan pendapatan pembudidayaan ikan sehingga menghasilkan kesetaraan terhadap setiap wilayah dan kualitas hidup dan kesejahteraan masyarat menjadi lebih baik.

\section{Daftar Pustaka}

Badan Pusat Statistik. (2018) Publikasi. Kabupaten Kutai Kartanegara Dalam Angka 2018

Bappenas. (2013) Pengembangan Kawasan Minapolitan Sekretariat Jendaral Kementarian Kelautan dan Perikanan.

Ridha, Rasyid, Nyoman U.V, IGN, Alit Wiswasta. (2016) 'Analisis Daya Dukung Lahan Sebagai Pengembangan Fasilitas Perkotaan Kecamatan Mpunda Kota Bima Tahun 2015 - 2035'. Jurnal Wilayah dan Linkungan Vol. 04 No. 01, April 2016, Hal: 65 - 80.

Tussa'diah, Halima. (2014) Analisis Skalogram Guttman Kabupaten Blora. https://www.academia.edu/26520432/Analisis_Skalogram_Guttman_Kabupaten_Blora. Diakses pada 20 November 2019. 